\title{
Microstructure and residual elastic strain at graphite nodules in ductile cast iron analyzed by synchrotron X-ray microdiffraction
}

Zhang, Y. B.; Andriollo, T.; Fæster, S.; Barabash, R.; Xu, R. ; Tiedje, N.; Thorborg, J.; Hattel, J.; Juul Jensen, D.; Hansen, N.

Published in:

Acta Materialia

Link to article, DOI:

10.1016/j.actamat.2019.01.038

Publication date:

2019

Document Version

Peer reviewed version

Link back to DTU Orbit

Citation (APA):

Zhang, Y. B., Andriollo, T., Fæster, S., Barabash, R., Xu, R., Tiedje, N., Thorborg, J., Hattel, J., Juul Jensen, D., \& Hansen, N. (2019). Microstructure and residual elastic strain at graphite nodules in ductile cast iron analyzed by synchrotron X-ray microdiffraction. Acta Materialia, 167, 221-230.

https://doi.org/10.1016/j.actamat.2019.01.038

\section{General rights}

Copyright and moral rights for the publications made accessible in the public portal are retained by the authors and/or other copyright owners and it is a condition of accessing publications that users recognise and abide by the legal requirements associated with these rights.

- Users may download and print one copy of any publication from the public portal for the purpose of private study or research.

- You may not further distribute the material or use it for any profit-making activity or commercial gain

- You may freely distribute the URL identifying the publication in the public portal 
Microstructure and residual elastic strain at graphite nodules in ductile cast iron analyzed by synchrotron X-ray microdiffraction

Y.B. Zhang ${ }^{1 *}$, T. Andriollo ${ }^{1}$, S. Fæster ${ }^{2}$, R. Barabash ${ }^{3}$, R. Xu ${ }^{4}$, N. Tiedje ${ }^{1}$, J. Thorborg ${ }^{1}$, J. Hattel ${ }^{1}$, D. Juul Jensen ${ }^{1}$, N. Hansen ${ }^{2}$

${ }^{1}$ Department of Mechanical Engineering, Technical University of Denmark, DK-2800 Kgs. Lyngby, Denmark

${ }^{2}$ Department of Wind Energy, Technical University of Denmark, Ris $\varnothing$ Campus, Roskilde 4000, Denmark

${ }^{3}$ Materials Science \& Technology Division, Oak Ridge National Laboratory, P.O. Box 2008, Oak Ridge, Tennessee 37831-6118, USA

${ }^{4}$ Advanced Photon Source, Argonne National Laboratory, Lemont, Illinois 60439-4800, USA

*Email address: yubz@mek.dtu.dk; postal address: Technical University of Denmark, Produktionstorvet, Building 425, room 214, 2800 Kgs. Lyngby, Denmark. Phone: +45 45254752.

Abstract: The microstructure and residual elastic strain at graphite nodules (GNs) in ductile cast iron produced using either a fast or slow cooling rate have been characterized using synchrotron 3D X-ray Laue microdiffraction. The results show that thermal stress is introduced during cooling and that part of this stress is relaxed by plastic deformation of the polycrystalline ferrite matrix. It is found that the plastic deformation is accommodated by the formation of dislocations and dislocation boundaries, which are organized in a cell structure. The dislocation density quantified based on the microstructure is most pronounced at the GN/matrix interface around small GNs in the fast cooled sample. Residual elastic strain is also present, which is mainly compressive with a maximum of $6.0-9.9 \times 10^{-4}$ near the GNs. Gradients of plastic deformation and elastic strain field around the GNs are observed. The results document for the first time that both the elastic strain field and the plastic strain field averaged over the grains around the GNs is approximately scaling with GN size and not affected by the cooling rate. The experimental data are compared with simulations by a finite element method, and agreement and disagreement are discussed in detail. 
Keywords: Cast iron; Residual strain/stress; Plastic deformation; Dislocation density; Differential aperture X-ray microscopy (DAXM)

\section{Introduction}

Ductile cast iron (DCI) is used widely in industrial products such as automobiles and wind turbines, due to its versatility and good performance with a combination of strength, ductility and toughness at low cost [13]. Nowadays, more than $70 \mathrm{wt} \%$ of the worldwide production of casting alloys is cast iron, where more than 1/3 is DCI [3]. An example of industrial application is the heavy components in the drivetrain for wind turbines. These components typically experience highly dynamic and time-varying loads, and may fail due to fatigue, leading to very costly unplanned shutdown repairs. For these reasons, fatigue resistance is essential for such components [4].

Microstructurally, DCI consists of graphite nodules (GNs) in a metal matrix, which can be either ferrite, pearlite or a mixture of the two. Local residual stress may develop during cooling due to a difference in thermal expansion coefficient between the metal matrix and GNs [5-7]. However, residual stress may also have its origin in phase transformation during cooling and a volume growth of the GNs, as carbon releases from the austenite and diffuses into the GNs [8]. The stress can be higher than the flow stress of the matrix and lead to plastic deformation of the matrix by emission of and interaction with dislocations (see e.g. [911]), which relaxes the stress. Recent studies using synchrotron X-ray micro-diffraction have shown for the first time that the stress around the soft GNs can lead to plastic deformation of the matrix grains around the GNs, and that the residual stress at GNs can be as large as half of the yield stress of the matrix $[12,13]$. This observation suggests that local thermal residual stress has to be considered when designing cast iron components.

Additionally, the cooling rate is known to be an important processing parameter influencing the microstructure and properties of DCI [14-16]. It has been found in a large industrial project that DCI components cast in a metal mold have a higher fatigue resistance than identical components cast in a sand mold [14]. The cause of this difference may be related to the cooling rate, being fast when casting in a metal mold and significantly slower when using a sand mold. With reference to the behavior of metal matrix 
composites strengthened by hard particles [17], another parameter which may be of importance is the size of the GNs. However, it is unknown how the cooling rate and size of GNs affect the local stress and strain in DCI because the particles are soft. This knowledge is essential for optimization of the processing route and mechanical properties of DCI and for the development of analytical and numerical models relating processing conditions and properties of DCI.

Following previous studies [12,13], the synchrotron 3D technique, differential aperture X-ray microdiffraction (DAXM) [18-20], is used here to characterize the microstructure and elastic strain of the matrix grains around 5 fully embedded GNs with different sizes in two DCI samples manufactured with different cooling rates by using either a sand or metal casting mold. As DAXM provides both a high angular resolution $\left(0.01^{\circ}\right)$ and a high strain resolution $\left(1 \times 10^{-4}\right)$, the plastic deformation as well as the elastic strain gradients in the matrix grains near the GNs can be quantified. These two samples are chosen because their cooling rates are significantly different. As a result, the GN size and size distribution in the two samples are very different, allowing a GN size effect to be studied experimentally. To underpin parts of the experimental results, a finite element method (FEM) [21,22] is used to model the effects of cooling rate and GN size on the magnitude and distribution of the elastic strains in the structure.

\section{Experimental}

\subsection{Materials}

Two samples with the same geometry were prepared from the same melt, i.e. with the same chemical composition, but cast in different molds: a metal mold (mDCI) and a sand mold (sDCI). The size of the molds is large, app. $2.6 \mathrm{~m} \times 2.6 \mathrm{~m} \times 4.5 \mathrm{~m}$. The wall thickness of the cast components is of the order of 100 $200 \mathrm{~mm}$ and at some locations even thicker. For such heavy components, the local cooling rate in the temperature range $810-500{ }^{\circ} \mathrm{C}$ can only be estimated qualitatively to be $\sim 20$ times faster for $\mathrm{mDCI}$ than for sDCI (see Ref. [14] for more information), and therefore mDCI and sDCI are referred to in the following as fast and slow cooling rate castings, respectively. The chemical composition of the material is listed in Table 1. In both samples, most of the GNs were spherical and distributed homogeneously in the matrix with a 
volume fraction of $\sim 12 \%$ (see Fig. A1 in Appendix). Both the matrix grains and GNs were larger in sDCI than in $\mathrm{mDCI}$ (see Table 2). Both samples contain about $5 \%$ pearlitic domains.

Table 1. Chemical composition of the sample (wt\%).

\begin{tabular}{ccccccccccccccc}
\hline $\mathrm{C}$ & $\mathrm{Si}$ & $\mathrm{Mn}$ & $\mathrm{P}$ & $\mathrm{S}$ & $\mathrm{Cr}$ & $\mathrm{Ni}$ & $\mathrm{Co}$ & $\mathrm{Cu}$ & $\mathrm{Ti}$ & $\mathrm{V}$ & $\mathrm{Mg}$ & $\mathrm{Ce}$ & $\mathrm{Se}$ & $\mathrm{Fe}$ \\
\hline 3.68 & 2.30 & 0.22 & 0.01 & 0.01 & 0.02 & 0.04 & 0.02 & 0.01 & 0.01 & 0.01 & & 0.04 & 0.04 & Bal. \\
& & & 5 & 1 & 7 & 8 & 4 & 6 & 7 & 4 & & 2 & 3 & \\
\hline
\end{tabular}

Table. 2 Average and maximum size of the GNs and matrix grains in the two DCI samples.

\begin{tabular}{cccccc}
\hline & \multicolumn{2}{c}{ Average $(\mu \mathrm{m})$} & & \multicolumn{2}{c}{ Maximum $(\mu \mathrm{m})$} \\
\cline { 2 - 3 } \cline { 5 - 6 } & GNs & Matrix & & GNs & Matrix \\
\hline mDCI & 30 & 30 & & 80 & 115 \\
sDCI & 70 & 50 & & 300 & 200 \\
\hline
\end{tabular}

\subsection{Laboratory X-ray tomography}

To prepare specimens for the synchrotron measurements, the 3D distribution of GNs was first characterized by X-ray tomography using a Zeiss Xradia 520 Versa micro-CT system. For the CT scans, a polychromatic conical beam with X-ray energies up to $140 \mathrm{keV}$ was used with 1401 image projections over a rotation angle of $360^{\circ}$. Based on the CT scans, three GNs with sizes (equivalent spherical diameter (ESD)) of approx. 30 $\mu \mathrm{m}, 50 \mu \mathrm{m}$ and $70 \mu \mathrm{m}$ from mDCI and two GNs with sizes of approx. $80 \mu \mathrm{m}$ and $150 \mu \mathrm{m}$ from sDCI were selected. The GNs are referred to as GNs I-V, ordered according to size from small to large (see Table 3). All GNs were spherical and located close to the specimen surface but fully embedded in the bulk (see Fig. 1). The local GN volume fraction within the volumes in Fig. 1 is higher than the average volume fraction of the samples for GNs II and IV (see Table 3). 
Table 3 Parameters of the samples, the selected GNs and their surrounding matrix.

\begin{tabular}{ccccc}
\hline Cooling rate & GN & $\begin{array}{c}\text { Local GN } \\
\text { volume fraction } \\
(\%)\end{array}$ & $\begin{array}{c}\text { GN size, ESD } \\
(\mu \mathrm{m})\end{array}$ & Matrix grain size $(\mu \mathrm{m})$ \\
\hline \multirow{3}{*}{ mDCI } & I & 8.7 & 28 & 12 \\
& II & 13.9 & 48 & 26 \\
& III & 10.8 & 70 & 32 \\
\hline \multirow{2}{*}{ sDCI } & IV & 16.1 & 84 & 43 \\
& V & 11.6 & 149 & - \\
\hline
\end{tabular}
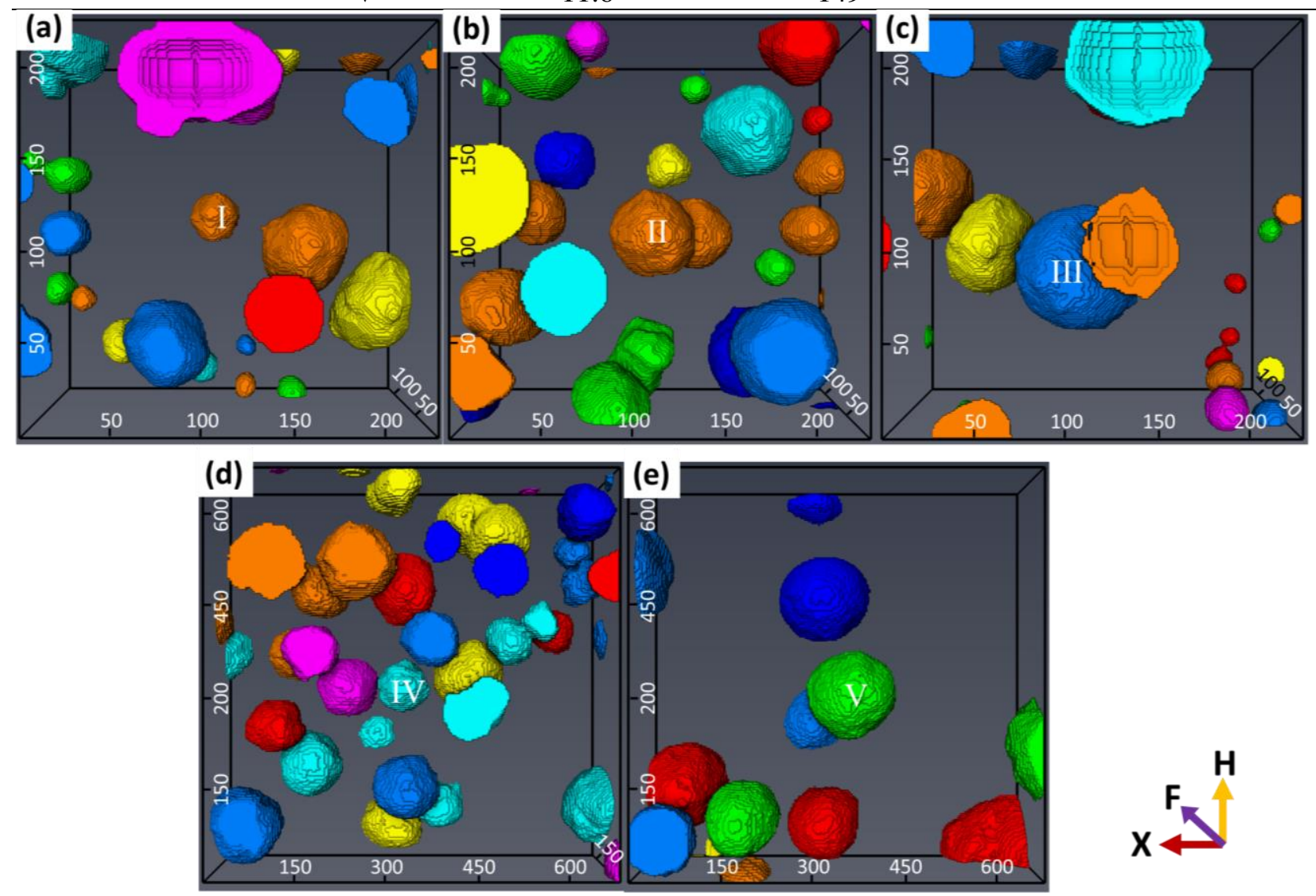

Fig. 1 Micrographs obtained by laboratory X-ray tomography showing 3D images of GNs in the two samples. The selected five GNs are marked by numbers: (a)-(c) are from mDCI, while (d) and (e) are from sDCI. The segmentation of the GNs is conducted using the Avizo® software, based on the intensity of the 3D tomography data. In each case the GNs are colored randomly. The size of the mapped volumes is $227 \times 227 \times 113 \mu \mathrm{m}^{3}$ in (a)-(c) and $670 \times 670 \times 170 \mu \mathrm{m}^{3}$ in (d) and (e). The front faces of the volumes are the specimen surfaces. 


\subsection{Synchrotron experiments}

The DAXM experiments were performed at beamline 34-ID-E at the Advanced Photon Source (APS), Argonne National Laboratory, USA [23]. The specimens were mounted on an inclined sample holder at a $45^{\circ}$ incidence angle to the incoming X-ray beam, and were scanned horizontally (along X in Fig. 2) by moving the sample stage in steps of $1 \mu \mathrm{m}$. One section through each of the selected GNs was scanned. Considering the X-ray absorption of the iron matrix (with a mean penetration depth about $100 \mu \mathrm{m}$ ), the selection of the scanning position depends on the GN size (see Fig. 2). More details about the experimental setup, including the specification of the microbeam and detector (for recording the Laue diffraction patterns), can be found in [12,24].

(a)

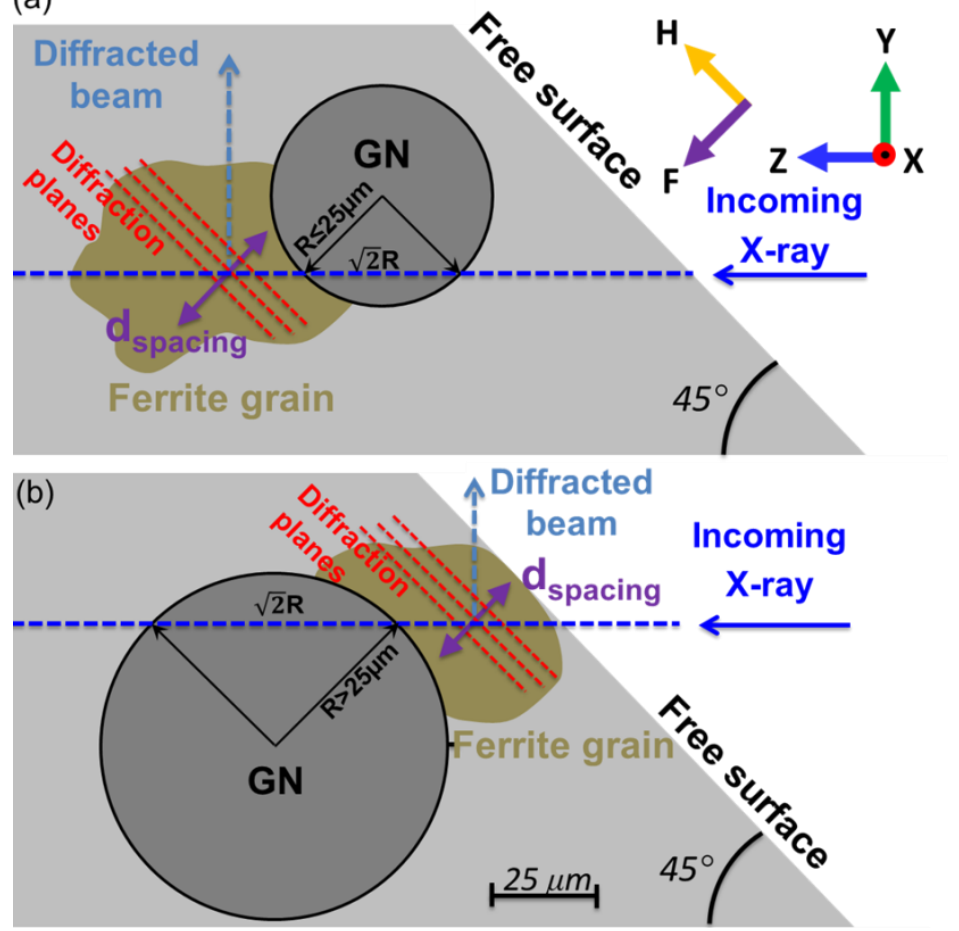

(c)

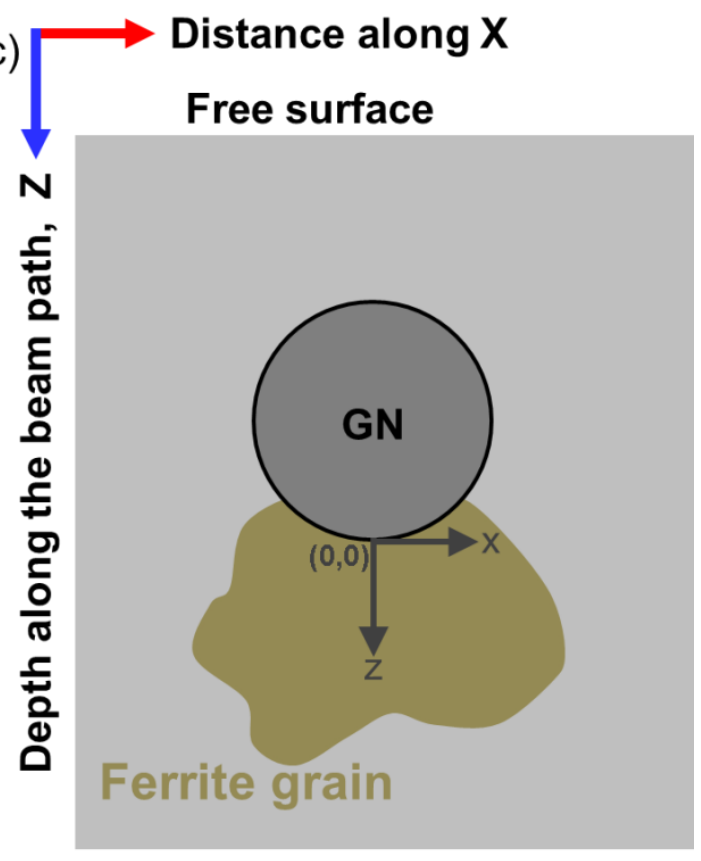

Fig. 2 Sketch showing the details of the experimental set-up in the beamline coordinate system (X, Y, Z). (a) and (b) show the geometrical relation between the synchrotron X-ray scanning planes (the projections of which are shown as blue dashed lines) and the selected GNs (gray spheres) for cases where the radius of the $\mathrm{GN}, R_{\mathrm{GN}}=\mathrm{ESD} / 2$, is smaller and larger than $25 \mu \mathrm{m}$, respectively. Ferrite grains (tan regions) with their lattice planes (shown as red dashed lines) roughly parallel to the specimen surface selected for monochromatic energy scans are also marked. (c) in-plane view of the X-ray scanning section of a GN embedded in the 
metal matrix for case of $R_{\mathrm{GN}} \leq 25 \mu \mathrm{m}$. A new coordinate system (x, z), with x along the tangential direction and $\mathrm{z}$ along the radial direction of the GN, is defined for the selected matrix grain with the origin at matrix/GN interface. The specimen coordinates (X, H, F) shown in (a) are the same as those in Fig. 1.

To resolve the diffraction pattern from each volume element at different depths, a Pt-wire with a diameter of $100 \mu \mathrm{m}$ was used as a differential aperture and scanned at a distance of $\sim 250 \mu \mathrm{m}$ from the specimen surface. The reconstruction and indexing of the Laue patterns at each depth were conducted using the LaueGo software at the APS beamline 34-ID-E [25], to a depth of $\sim 100 \mu \mathrm{m}$ into the specimens with a step size of 1 $\mu \mathrm{m}$. Both polychromatic and monochromatic beam modes were used in the present study: a polychromatic beam was used to determine the orientations of the matrix grains around the GNs, and a monochromatic beam was for determining the absolute crystallographic plane spacing, hence the elastic strain. More details about the experimental procedure of the strain measurements are described elsewhere $[18,26]$. For the present study, absolute lattice plane spacings along directions roughly parallel (maximum $3^{\circ}$ off) to the specimen normal direction (ND) were determined for selected matrix grains as illustrated in Fig. 2.

Following the previous study [12], an unstrained lattice parameter $a_{0}=2.8653 \AA$ was used for the calculation of elastic strain. This value is determined based on the chemical composition of the sample using an empirical equation reported in Ref. [27].

\section{Results}

\subsection{Depth-dependent grain orientation distribution from polychromatic scans}

Grain orientation maps characterized using DAXM are shown in Figs. 3 and 4 for mDCI and sDCI, respectively. The matrix around the selected GNs is shown in color and the GNs are seen as large black regions. Several neighboring GNs are also seen. In general, the matrix grains are well indexed, except small parts from deep volumes due to weak signals. With the high angular precision of DAXM $\left(\sim 0.01^{\circ}\right)[18]$, dislocation boundaries with low misorientation angles are revealed. An angle of $\sim 0.1^{\circ}$ is used to reveal the dislocation structure, and a cut-off angle of $3^{\circ}$ is used for defining grain boundaries in the matrix. In mDCI, 
most of the grains contain many dislocation boundaries with misorientation angles below $1^{\circ}$, while in sDCI the grains contain fewer dislocation boundaries (see Figs. 3 and 4).

The number of matrix grains around each GN in both samples is quite similar within the characterized section, about 5-7. The average grain size of the matrix grains, $D_{\text {Grain }}$, around the GNs is about half of the GN size (see Table 3). Within grains, most of the dislocation boundaries are organized into a cell structure, and the cell size is smaller in $\mathrm{mDCI}$ than in sDCI. For mDCI, more cell boundaries with misorientation $>1^{\circ}$ are seen around the smallest GN I than around the larger GNs II and III.

Within the cells, small orientation variations are observed, especially in the cells near the GN/matrix interface. Some examples of misorientation angles at the interface measured along the lines marked in Figs. 3 and 4 are shown in Fig. 5. For most cases, the angle increases monotonically with increasing distance from the interface, indicating the presence of a strain gradient.

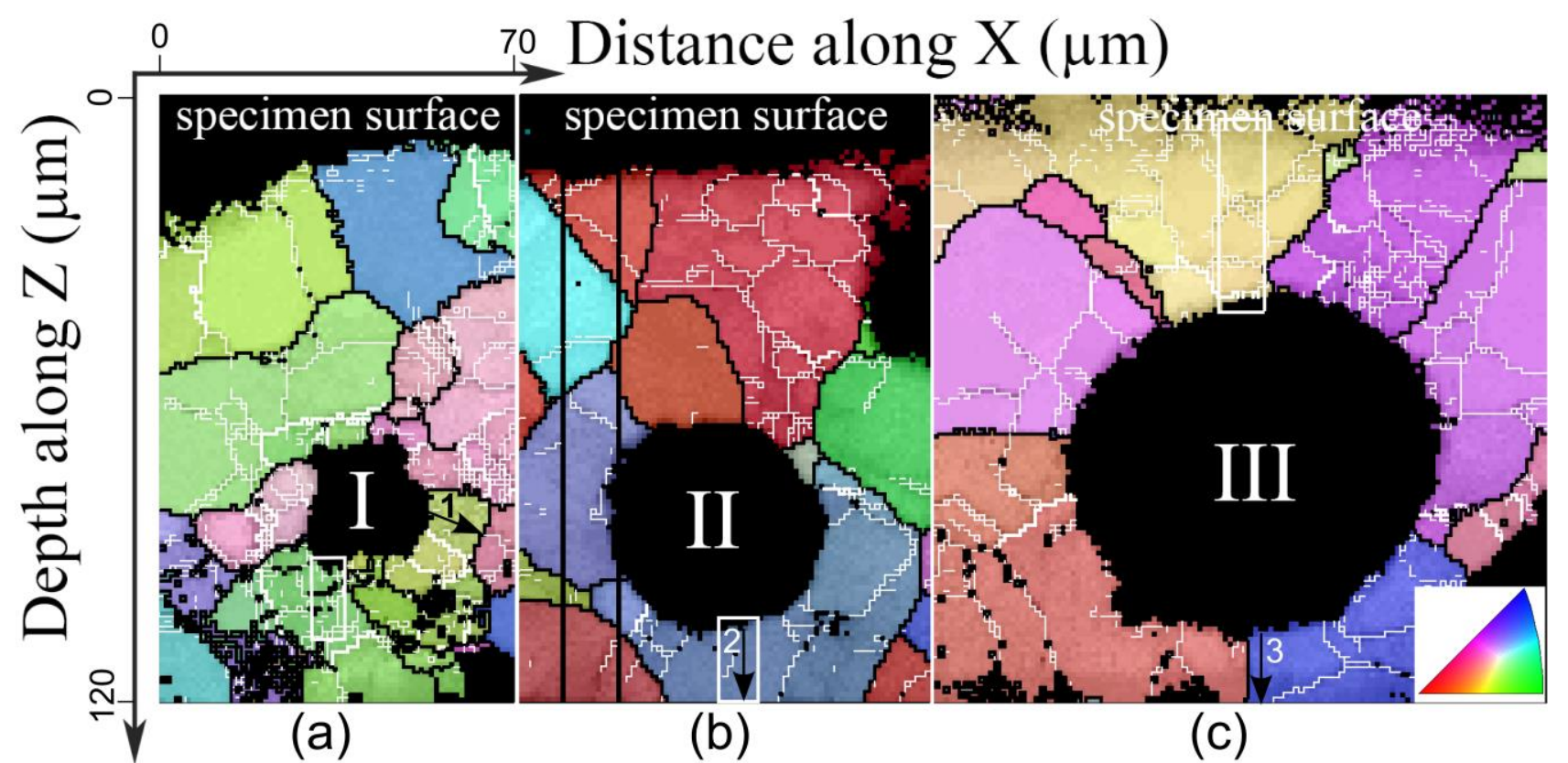

Fig. 3. Microstructures of mDCI characterized using DAXM. (a) - (c) showing microstructures around the selected GNs, I - III, respectively. In the maps, dislocation boundaries with misorientation angles in the range of $0.1-1^{\circ}, 1-3^{\circ}$, and $>3^{\circ}$ are shown in thin white, thick white and thick black lines, respectively. The colors of the matrix grains correspond to the crystallographic orientation along the specimen normal direction (F direction in Fig. 1). The color code is shown in the inset in (c).The black pixels in the matrix 
away from the GNs are non-indexed. The three white boxes mark regions where monochromatic energy scans were performed. The black lines numbered as 1- 3 in (a)-(c), respectively, mark positions, along which the misorientation profile is shown in Fig. 5.

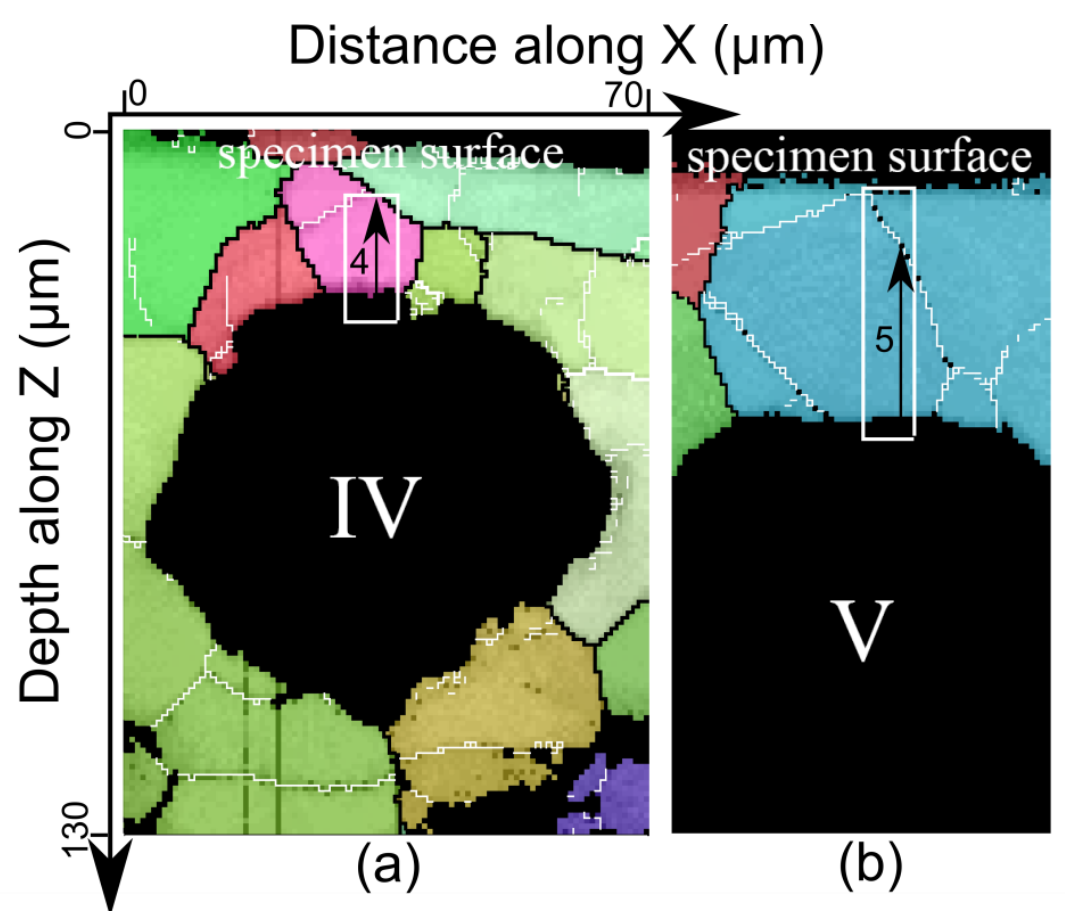

Fig. 4. Microstructures of sDCI characterized using DAXM. (a) and (b) showing microstructures around the selected GNs, IV and V, respectively. The boundaries and colors of the matrix grains are the same as those in Fig. 3. The two white boxes mark regions where monochromatic energy scans were conducted. The black lines numbered as 4 and 5 in (a) and (b), respectively, mark positions, along which the misorientation profiles are shown in Fig. 5. 


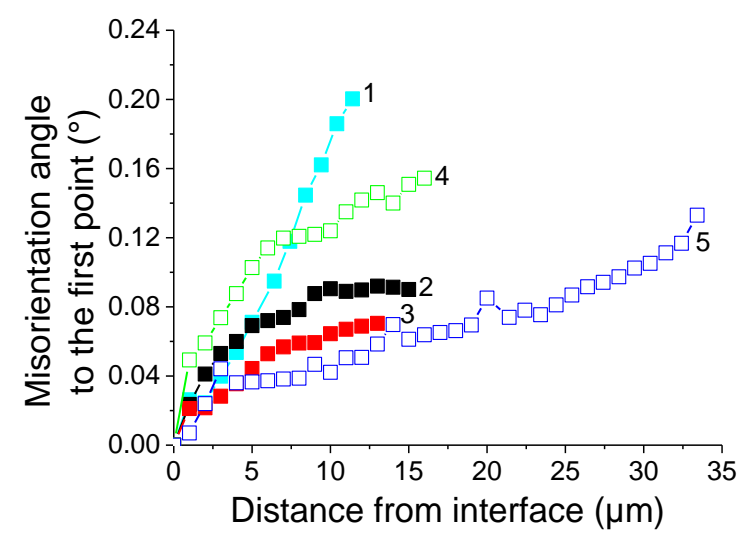

Fig. 5 Orientation change with distance from the GN/matrix interface along the five black lines marked in Figs. 3 and 4.

\subsection{Quantification of structural parameters in the deformed microstructure}

The high-angular-resolution maps shown in Figs. 3 and 4 allow quantification of structural parameters locally around the GNs. For this quantification, misorientations between neighboring pixels with angles in the range $0.01-3^{\circ}$ are included. Boundaries with misorientation $\geq 3^{\circ}$ are excluded, as these most likely are grain boundaries originating from the austenite to ferrite phase transformation. Also, the pearlite structure around GN I is not included, as it is poorly indexed (black pixels in Fig. 3a) and only accounts for 5vol\% in the sample.

The structural quantification to be given in the following covers average values for the whole areas characterized. The average misorientation angles (defined as the mean of the misorientation angles between all pairs of nearest neighbor pixels) within the cells and across cell-wall boundaries are calculated separately (see Table 4). By comparing the data for different samples and GN sizes, it is seen that an increase in cooling rate leads to relatively more pronounced plastic deformation: i) the average misorientation angles within the cells are higher in $\mathrm{mDCI}$ than in sDCI; ii) the average cell size in the matrix grains increases with increasing GN size, and the average cell size for $\mathrm{SDCI}$ is about twice that for $\mathrm{mDCI}$. However, the cooling rate has a minor effect on the average misorientation angles across the cell-wall boundaries. Considering effects of the GN size, it is seen that a decrease in GN size results in relatively more pronounced plastic deformation: the average misorientation angles within the cells, across cell-walls and for the whole matrix (both across cell 
walls and within cells) are in general higher around the smaller GNs, in both samples. At the same time, the contribution of misorientations within the cells to the average misorientation angles for the whole matrix increases with increasing GN size.

Table 4. Quantification of misorientation variations, cell size and dislocation density for the characterized areas around the 5 GNs (see Figs. 3 and 4). The uncertainty for the misorientation angles is the standard deviation, while the uncertainty for the dislocation density is estimated based on the calculation at 4 different sub-regions of the maps. The cell size is measured as the intercept length.

\begin{tabular}{|c|c|c|c|c|c|}
\hline \multirow[b]{2}{*}{ GNs } & \multicolumn{3}{|c|}{ Average misorientation angle } & \multirow{2}{*}{$\begin{array}{c}\text { Average } \\
\text { dislocation } \\
\text { density }\left(\times 10^{12} \mathrm{~m}^{-2}\right)\end{array}$} & \multirow[t]{2}{*}{ Cell size $(\mu \mathrm{m})$} \\
\hline & Within cells & $\begin{array}{l}\text { Across cell- } \\
\text { walls }\end{array}$ & Whole matrix & & \\
\hline $\mathrm{I}$ & $0.025 \pm 0.003^{\circ}$ & $0.56 \pm 0.04^{\circ}$ & $0.10 \pm 0.004^{\circ}$ & $14.1 \pm 0.6$ & $8.7 \pm 2.6$ \\
\hline II & $0.020 \pm 0.001^{\circ}$ & $0.38 \pm 0.04^{\circ}$ & $0.05 \pm 0.014^{\circ}$ & $7.0 \pm 1.9$ & $10.8 \pm 1.0$ \\
\hline III & $0.020 \pm 0.001^{\circ}$ & $0.44 \pm 0.02^{\circ}$ & $0.06 \pm 0.006^{\circ}$ & $8.4 \pm 0.8$ & $10.9 \pm 2.3$ \\
\hline IV & $0.017 \pm 0.001^{\circ}$ & $0.50 \pm 0.04^{\circ}$ & $0.04 \pm 0.004^{\circ}$ & $5.6 \pm 0.6$ & $18.8 \pm 5.5$ \\
\hline V & $0.011 \pm 0.001^{\circ}$ & $0.37 \pm 0.07^{\circ}$ & $0.02 \pm 0.014^{\circ}$ & $3.2 \pm 1.9$ & - \\
\hline
\end{tabular}

As described in [28-30], the average dislocation density, $\rho$, of unpaired dislocations in the cell walls and within the cells can be quantified based on the misorientation angle, $\theta$, using Eq. (1):

$$
\rho=\alpha / u \cdot \theta / b
$$

where $\alpha$ is a constant and typically equals 2 [28], $u$ is a unit length, and $b$ is the Burgers vector $(0.248 \mathrm{~nm})$. For this calculation, the average misorientation for the whole matrix is used, including misorientations within the cells and across cell-walls. As shown in Table 4, the dislocation densities are in general higher around the smaller GNs in both samples. The average dislocation density is about $10 \times 10^{12} \mathrm{~m}^{-2}$ and $5 \times 10^{12} \mathrm{~m}^{-2}$ for $\mathrm{mDCI}$ and sDCI, respectively (see Table 4).

To reveal the difference in plastic deformation locally around the GNs, the dislocation densities for regions of $0-5,5-10,10-20$, and $>20 \mu \mathrm{m}$ from the GN/matrix interfaces have been calculated (see Fig. 6). For both samples, the dislocation densities in the matrix decrease with increasing distance from the GN/matrix interface, pointing to a gradient in plastic strain. Note also in Fig. 6 that the strain gradient is affected by the GN size and is very pronounced for the smallest GN I. 


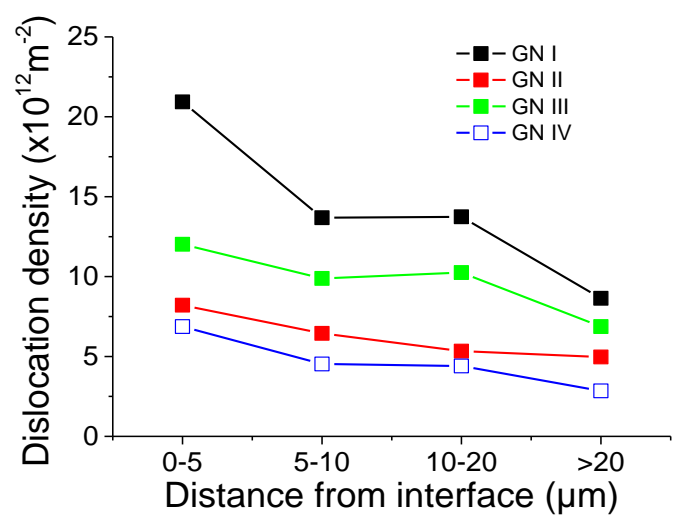

Fig. 6 Local average unpaired dislocation density as a function of distance from the GN/matrix interface. The dislocation densities are calculated using Eq. 1 based on average misorientation angles over the specified areas, including both misorientations across the cell boundaries and within the cells, for regions at different distances from the GN/matrix interface.

\subsection{Residual elastic strain}

The residual elastic strains within the grains marked by white boxes in Figs. 3 and 4 have been measured using monochromatic energy scans. These grains were chosen because they are located at GN/matrix interfaces nearly parallel to the specimen surface (see Fig. 2). For the monochromatic energy scans, one diffraction vector more or less parallel to the specimen surface normal direction (ND) was chosen for each selected grain (see Fig. 2 and Table 5). The measured strain component is therefore roughly along the radial direction of the GNs.

The measured residual elastic strain as a function of distance from the GN/matrix interface is shown in Fig. 7, where different line profiles are along different vertical lines (along the radial direction $\mathrm{z}$ and separated by $2 \mu \mathrm{m}$ along the tangential direction, $\mathrm{x}$ defined in Fig. 2c) within the boxes marked in Figs. 3 and 4. Except for the data for GN I, which show enhanced noise due to the relatively weak diffracted X-ray signal from volumes deep inside the specimen, the general trend is the same: for all the grains, a predominately compressive strain is observed with gradients along the radial direction. Only a small region showing a tensile strain in the order of $1.5-2 \times 10^{-4}$ is seen for GN III near the sample surface, which is likely to be a result of surface deformation during polishing (see section A in the supplementary materials). The largest compressive strain is $-9.9 \times 10^{-4}$ and $-7.1 \times 10^{-4}$ at GNs III and V in mDCI and sDCI, respectively. Note that 
the maximum compressive strains for sDCI are located about 8 and $14 \mu \mathrm{m}$ from the GN/matrix interface for the grains at GNs IV and V, respectively. A similar behavior is seen for the grain at GN II in mDCI. In both cases, the change in the strain gradient occurs at a distance of about $10-20 \%$ of the GN radius $\left(R_{\mathrm{GN}}\right)$. The average strain at $20 \% R_{\mathrm{GN}}$ along $\mathrm{z}$ is similar for $\mathrm{mDCI}$ and $\mathrm{sDCI}$, except for GN I (see Table 5).

Table 5. The crystallographic direction approximately normal to the specimen surface, the directional Young's moduli and the residual elastic strain/strain gradients for the five selected matrix grains marked by the white boxes in Figs. 3 and 4. Errors represent the standard deviation.

\begin{tabular}{cclccc}
\hline GNs & $\begin{array}{c}\text { Crystallographic } \\
\text { direction of } \\
\text { matrix grain }\end{array}$ & $\begin{array}{l}\text { Directional } \\
\text { Young's } \\
\text { modulus } \\
(\mathrm{GPa})\end{array}$ & $\begin{array}{c}\text { Maximum } \\
\text { compressive } \\
\text { strain } \\
\left(\times 10^{-4}\right)\end{array}$ & $\begin{array}{c}\text { Strain at } \\
z / R_{\mathrm{GN}}=0.2 \\
\left(\times 10^{-4}\right)\end{array}$ & $\begin{array}{c}\text { Strain gradient } \\
\text { between } z / R_{\mathrm{GN}}=0.2 \\
\text { and } 0.5\left(\times 10^{-4}\right)\end{array}$ \\
\hline I & 136 & 183 & -6.0 & $-4.6 \pm 0.8$ & $-0.5 \pm 0.6$ \\
II & 325 & 220 & -8.0 & $-5.8 \pm 0.6$ & $1.8 \pm 0.6$ \\
III & 316 & 183 & -9.9 & $-5.7 \pm 0.8$ & $1.9 \pm 0.4$ \\
IV & 226 & 176 & -7.1 & $-5.7 \pm 0.8$ & $2.3 \pm 0.6$ \\
V & 255 & 241 & -6.8 & $-6.2 \pm 0.5$ & $2.2 \pm 0.5$ \\
\hline
\end{tabular}
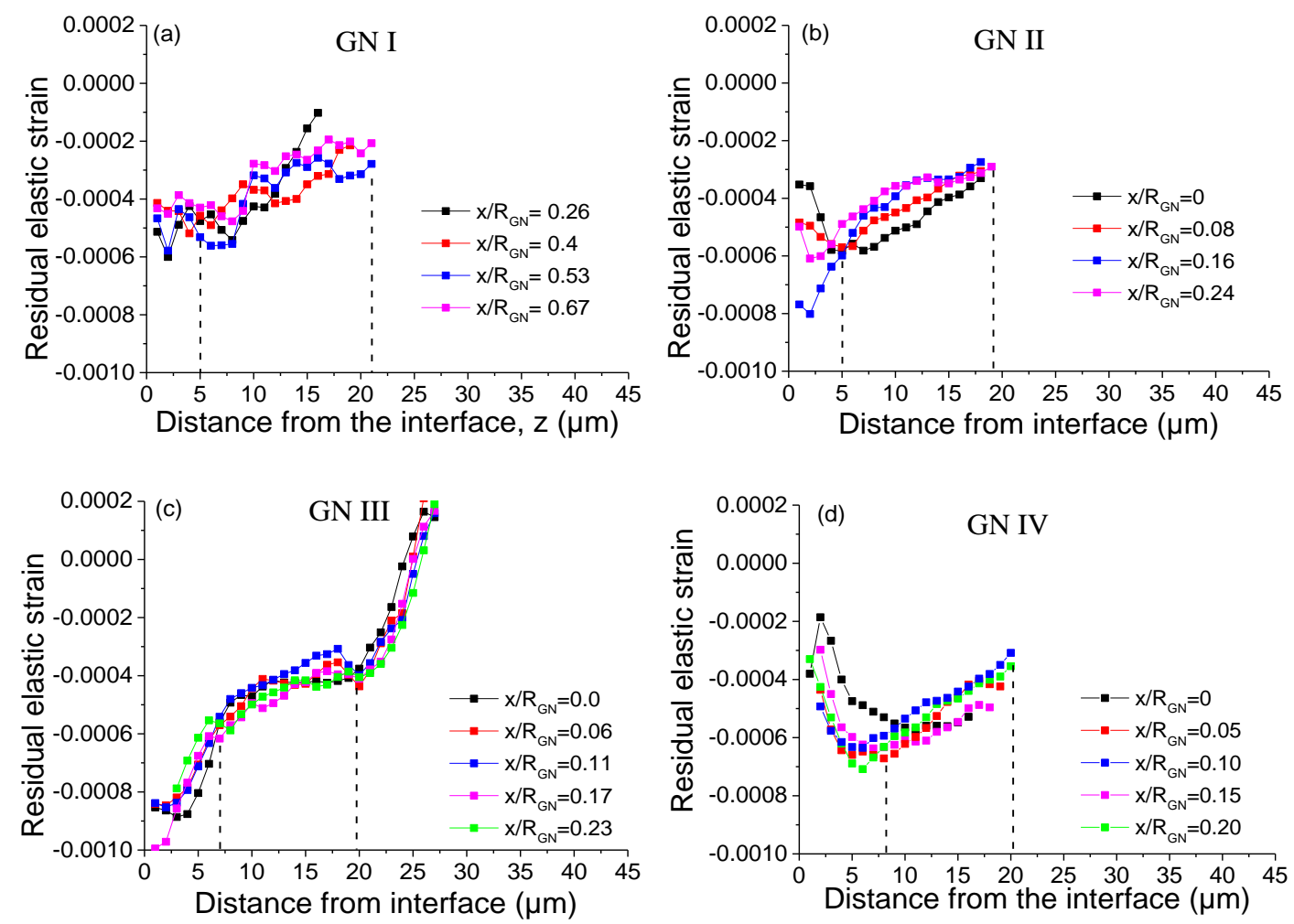


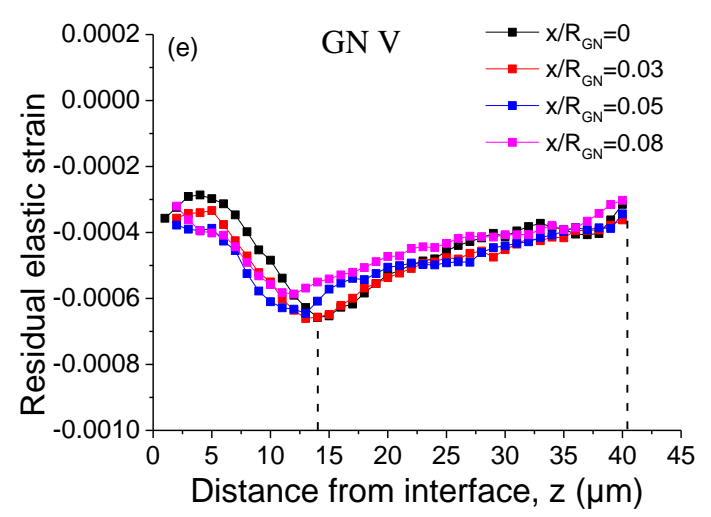

Fig. 7 Residual elastic strain as a function of distance from the GN/matrix interface along $\mathrm{z}$ measured for the matrix grains marked by white boxes in Figs. 3 and 4. Note that $\mathrm{x} / \mathrm{R}_{\mathrm{GN}}=0$ corresponds to the center of the nodule (see Fig. 2c). The dashed lines mark regions with relatively uniform strain gradients.

\section{Discussion}

\subsection{Effects of GN size and cooling rate on the elastic and plastic strain field}

The DAXM results show clearly the existence of residual elastic strain (see Fig. 7) in the matrix grains near GNs. The corresponding maximum stress values can be estimated based on directional Young's moduli (see Table 5), and are in the range 110-180 MPa. This range can be compared to the yield stress of the ferrite matrix, which is about $295 \mathrm{MPa}$ at room temperature [31]. The elastic stress builds up during solid-state cooling due to the difference in thermal expansion coefficient between ferrite and GN. An additional cause of the stress may be a growth of the GNs of about $10 \%$ due to the carbon diffusion from the austenite to GNs during cooling. However, this process occurs at temperatures above the phase transformation temperature $\left(\sim 800^{\circ} \mathrm{C}\right)$, where the austenite matrix is soft and the $\mathrm{GN}$ volume growth can be accommodated by matrix creep.

The DAXM results show a significant effect of GN size on the distribution of residual elastic strain/stress. However, when the measured elastic strain values (see Fig. 7) are replotted as a function of the normalized distance from the interface, $\mathrm{z} / \mathrm{R}_{\mathrm{GN}}$ (see Fig. 8), it is seen that within the range $\mathrm{z} / \mathrm{R}_{\mathrm{GN}}=0.2-0.5$ the curves largely overlap. On average, this is in good accord with the prediction by classic analytical models [32-35]. 
There is no apparent difference between $\mathrm{mDCI}$ and sDCI, suggesting that the cooling rate has a minor effect on the residual elastic strain. As the measurements for the $5 \mathrm{GNs}$ were conducted at different distances from the free sample surface, the fact that the data overlap suggests that stress relaxation near the surface also has a minor influence on the stress distribution near the GNs [36]. Within the range $\mathrm{z} / \mathrm{R}_{\mathrm{GN}}=0-0.2$, a large scatter in strain is seen. This observation may be related to the internal structure of the GNs (see Fig. A1 in Appendix), as demonstrated by the FEM simulations presented in section 4.3.

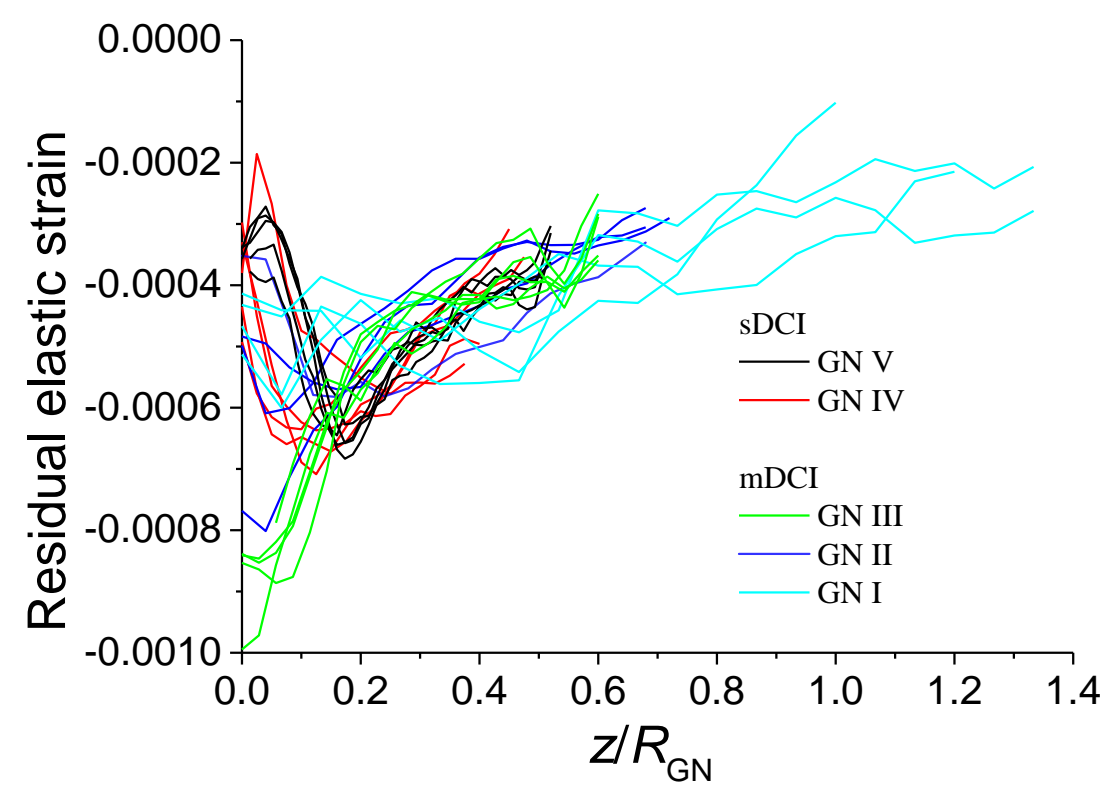

Fig. 8 Residual elastic strains as a function of normalized distance from $G N /$ matrix interface $\left(\mathrm{z} / \mathrm{R}_{\mathrm{GN}}\right)$ for the different GNs.

The DAXM results show also that the dislocation density in the ferrite matrix grains is affected by the GN size and the cooling rate (see Fig. 6 and Table 4). When the dislocation density is plotted as a function of the reciprocal GN size, $1 / R_{\mathrm{GN}}$, a reasonably good linear relationship is found for both the cases at the GN/matrix interface (i.e. $\mathrm{z} \approx 0$ ) and at $\mathrm{z} \approx 0.6 R_{\mathrm{GN}}$ (see Fig. 9). This $\mathrm{GN}$ size dependence can be elucidated based on the mechanism-based theory of strain gradient plasticity [29]. For volume expansion of spherical GNs, the density of geometrically necessary dislocations (GNDs), nucleated at the GN/matrix interface to accommodate the volume changes, is proportional to the strain gradient [29]: 


$$
\rho_{\mathrm{GND}} \propto-\frac{d \varepsilon^{P}}{d z}
$$

where $\varepsilon^{\mathrm{P}}$ is the plastic strain in the matrix, which is decreasing with increasing distance, $z$, from the GN/matrix interface. The linear relationship between the dislocation density $\rho_{\mathrm{GND}}$ and $1 / R_{\mathrm{GN}}$ in Fig. 9 implies that $\frac{d \varepsilon^{P}}{d z}$ is linear proportional to $1 / R_{\mathrm{GN}}$. Therefore the result suggests that the plastic strain field averaged over all matrix grains around the GNs is about the same for different GNs when normalized by $R_{\mathrm{GN}}$, i.e. the plastic strain field is scaling with the GN size, though locally different grains deformed differently (see Figs. 3 and 4).

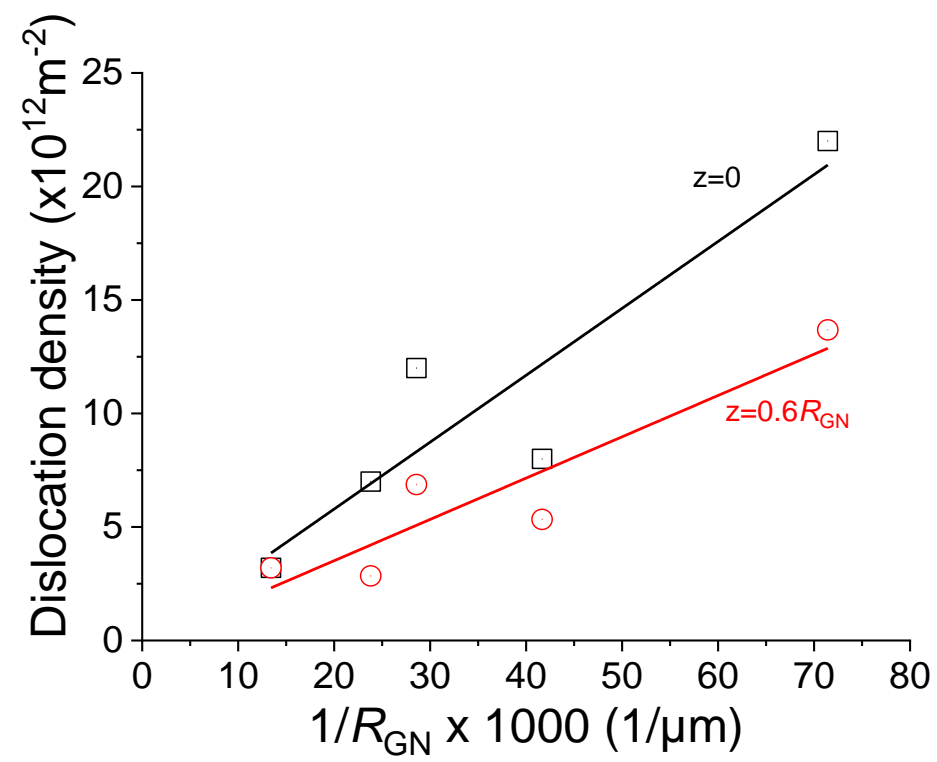

Fig. 9 Relationship between average local GN grain size, $R_{\mathrm{GN}}$, and local dislocation density at $\mathrm{z} \approx 0$ and $\mathrm{z} \approx$ $0.6 R_{\mathrm{GN}}$ (For GN V, the average dislocation density is used for the plot).

\subsection{FEM and comparison between experiments and modelling}

A two-scale hierarchical approach presented in [22] is adopted to predict the formation of the local thermal stress distribution. This approach consists of two main steps, which are carried out using two separate models - one at the macro-scale taking two cooling rates with a ratio of 20 into account, and one at the micro-scale taking the heterogeneous conical structure of a GN into account - connected in a sequential manner. Further details of the FEM implementation can be found in section B in the supplementary 
materials. In this paper, the focus is on the effects of cooling rate and GN internal structure, while the magnitude and the distribution of residual stress predicted by FEM is discussed in [22].

\subsubsection{Effect of internal structure of GNs}

GNs contain typically an internal structure composed of the so-called conical sectors [21,37], which are made of graphite plates stacking on each other with their $c$ axis aligned with the radial direction of the GNs. Experimentally, as the internal structure of GNs cannot be characterized by synchrotron X-rays, the X-ray grazing angles with respect to a conical sector of the GNs are therefore unknown. In this work, a few representative conditions (as shown in Fig. 10a) are thus used to show the influence of the internal structure of the GNs on the local residual elastic strains. The simulated residual elastic strains along these beam paths are shown in Fig. 11b for the fast cooling. It is evident that when the X-ray intersects at different angles to the conical sector of the GN, a large strain variation up to $1 \times 10^{3}$ can be seen locally within the range $\mathrm{z} / R_{\mathrm{GN}}$ $=0.1-0.2$. This variation is purely due to the local GN conical sector structure, which has been shown to introduce local mechanical anisotropy [38]. At $\mathrm{z} / R_{\mathrm{GN}}>0.2$, the variation between different beam paths is minor. At the same time, when the X-ray intersects at a fixed angle to the conical sector of a GN but at different position $\left(\mathrm{x} / \mathrm{R}_{\mathrm{GN}}\right)$ along the tangential $\mathrm{x}$ direction in the characterized section (see the coordinate definition Fig. 2c), some local strain variation can also be seen (see Fig. 10c). The amount of variation is similar to that shown in Fig. 10b. Both the $\mathrm{z} / \mathrm{R}_{\mathrm{GN}}$ range $(0-0.2)$ and the magnitude of strain fluctuation $\left(8 \times 10^{-}\right.$ ${ }^{4}$ ) in Fig. 10b and 10c are similar to the experimental result in Fig. 9. It is therefore likely that the experimental measured strain fluctuation within the range $\mathrm{z} / \mathrm{R}_{\mathrm{GN}}=0-0.2$ is a result of the local conical sector structure of the GNs.

\subsubsection{Effect of cooling rate}

The FEM simulations show that the effect of cooling rate on residual elastic strains is minor: the values are

only $5-10 \%$ higher for fast cooling than for slow cooling, and the strain gradients are the same (Figs. 10c and 10d). This is in good accord with the experimental observations (see Fig. 8). 
(a)
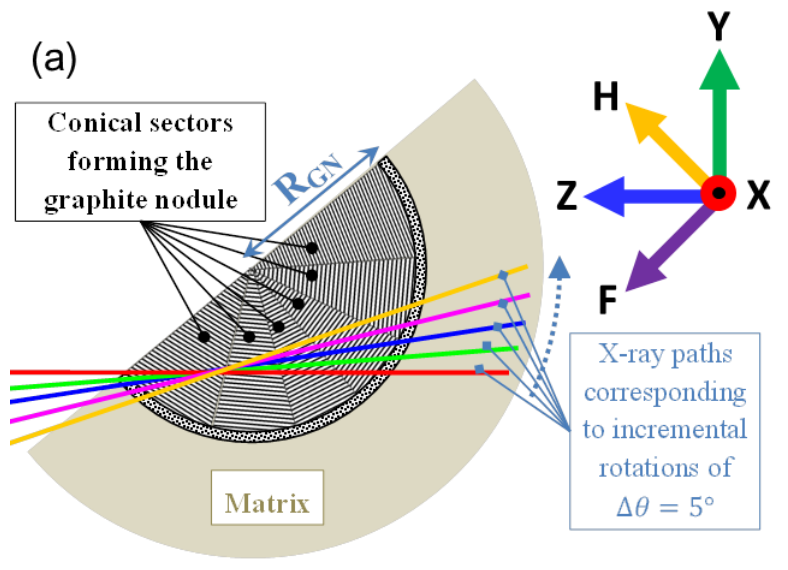

(c)

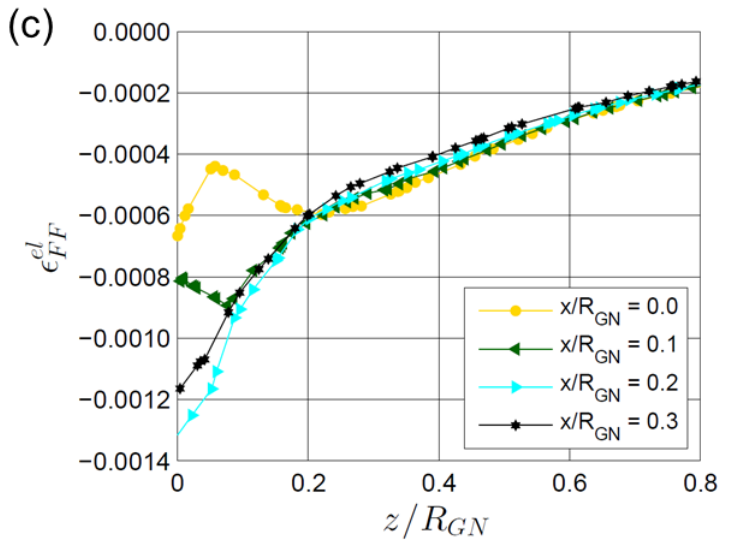

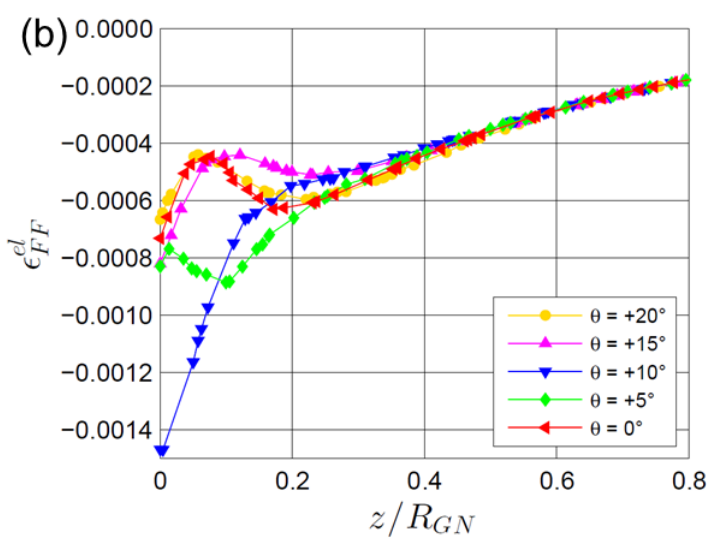

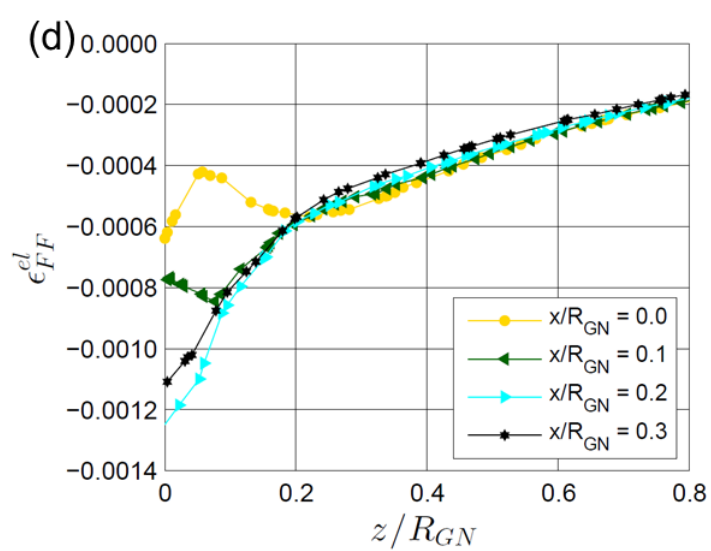

Fig. 10 FEM set-up and predicted residual strains. (a) Sketch showing the geometrical relationships between the incoming X-rays and the conical section structure of a GN. (b) FEM predicted residual elastic strains along the 5 different X-ray incoming paths as shown in (a). (c) and (d) are FEM predicted residual elastic strains along the path $\theta=20^{\circ}$ and at different $\mathrm{x} / \mathrm{R}_{\mathrm{GN}}$ for fast cooling rate and slow cooling rate, respectively.

\section{Conclusions}

In the present paper, the deformed microstructure and the local elastic strain have been analyzed using differential aperture X-ray microscopy (DAXM) at graphite nodules (GNs) in a ferritic matrix in ductile cast iron (DCI) processed by either fast or slow cooling in metal and sand molds, respectively. The conclusions are as follows:

i) Thermal contraction during cooling introduces an elastic strain at the GNs, which is partly relaxed by plastic deformation of the ferrite matrix grains at high temperature. Characteristic features of DCI are thus a residual elastic strain field at the GNs and a dislocation structure in the ferrite grains. The size of the GNs and the grain size are correlated and smaller in fast cooled than in slow cooled samples. 
ii) The maximum compressive elastic strain is in the range $6.0-9.9 \times 10^{-4}$ located at a distance from the surface of the GNs. It is not significantly affected by the cooling rate nor the GN size.

iii) The deformation structure in the ferrite grains is a dislocation cell structure with dislocations in the interior. The dislocation density in the ferrite grains at positions normalized by the GN size is proportional to the reciprocal GN size.

iv) Gradients in plastic deformation and elastic strain are seen around GNs. Both the elastic strain field and plastic strain field averaged over all the matrix grains around the GNs is scaling with the GN size, and is not affected by the cooling rate.

v) Comparison between finite element modeling and experimental results suggests that the internal structure of the GNs has a strong influence on the magnitude of the residual elastic strains only within the range of 0$20 \%$ of the GN radius, irrespective of the cooling rate.

\section{Appendix A:}

(a)

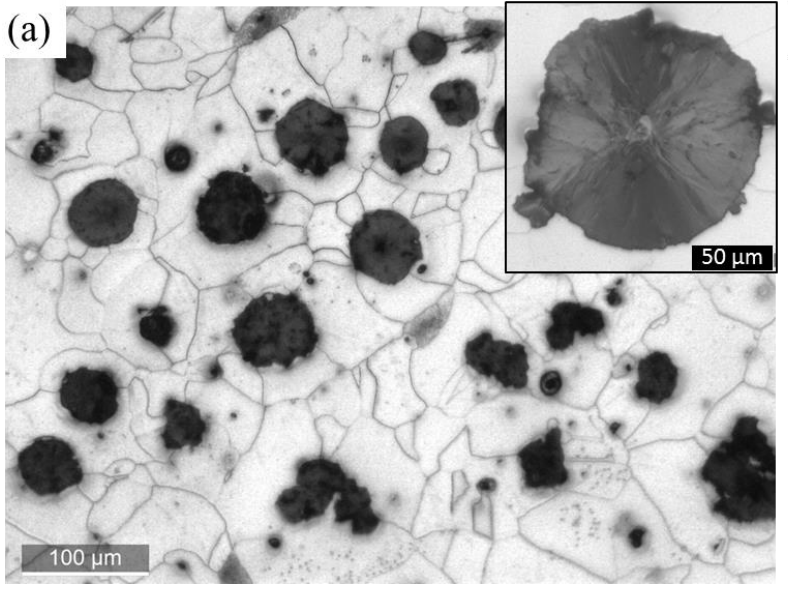

(b)

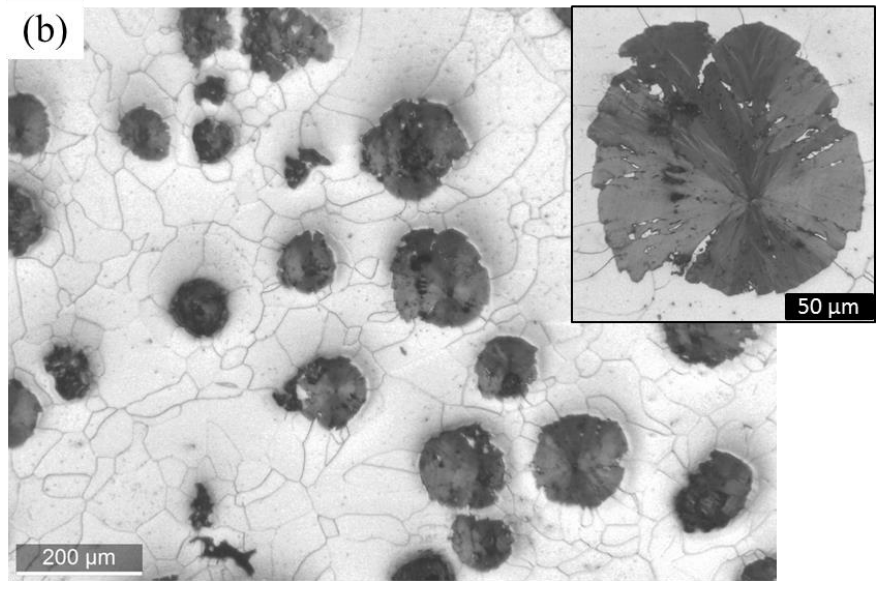

Fig. A1 Optical micrographs showing the microstructures of the two samples. (a) and (b) are for mDCI and sDCI, respectively. The insets show magnified images of GNs. Grain boundaries are seen as thin black lines.

\section{Acknowledgements}

This project was supported by the Danish Council for Independent Research Fund (8022-00340B). The instrument center Danscatt is acknowledged for travel funds to carry out the DAXM measurements (7055- 
00005B). Prof. Andy Godfrey is acknowledged for the valuable comments on the manuscript. Mr. Lars Lorentzen, DTU Wind Energy, is acknowledged for the help with sample preparation. Use of the Advanced Photon Source was supported by the U. S. Department of Energy, Office of Science, Office of Basic Energy Sciences, under Contract No. DE-AC02-06CH11357.

\section{References}

[1] C. Labrecque, M. Gagne, Review ductile iron: fifty years of continuous development, Can. Metall. Q. 37 (1998) 343-378. doi:10.1016/S0008-4433(98)00031-7.

[2] J.J. Gallagher, Ductile Iron Data for Design Engineers, Met. Int. Ltd. 44 (1998). doi:10.1037/h0091904.

[3] D.M. Stefanescu, ed., ASM Handbook, Volume 1A, Cast iron science and technology, ASM International, 2017.

[4] H. Rafsanjani, J. Sørensen, Reliability Analysis of Fatigue Failure of Cast Components for Wind Turbines, Energies. 8 (2015) 2908-2923. doi:10.3390/en8042908.

[5] S. Ho, E.J. Lavernia, Thermal residual stresses in metal matrix composites: A review, Appl. Compos. Mater. 2 (1995) 1-30. doi:10.1007/BF00567374.

[6] P.J. Withers, H.K.D.H. Bhadeshia, Residual stress. Part 2 - Nature and origins, Mater. Sci. Technol. 17 (2001) 366-375. doi:10.1179/026708301101510087.

[7] R.J. Arsenault, M. Taya, Thermal residual stress in metal matrix composite, Acta Metall. 35 (1987) 651-659. doi:10.1016/0001-6160(87)90188-X.

[8] V. Di Cocco, F. Iacoviello, A. Rossi, M. Cavallini, S. Natali, Graphite nodules and fatigue crack propagation micromechanisms in a ferritic ductile cast iron, Fatigue Fract. Eng. Mater. Struct. 36 (2013) 893-902. doi:10.1111/ffe.12056.

[9] C.Y. Barlow, N. Hansen, Deformation structures and flow stress in aluminium containing short whiskers, Acta Metall. Mater. 39 (1991) 1971-1979. doi:10.1016/0956-7151(91)90166-X.

[10] R.B. Calhoun, D.C. Dunand, Dislocations in Metal Matrix Composites, in: T.V. Clyne (Ed.), Compr. 
Compos. Mater., Elsevier, 2000: pp. 27-59.

[11] R.J. Arsenault, N. Shi, Dislocation generation due to differences between the coefficients of thermal expansion, Mater. Sci. Eng. 81 (1986) 175-187. doi:10.1016/0025-5416(86)90261-2.

[12] Y.B. Zhang, T. Andriollo, S. Fæster, W. Liu, J. Hattel, R.I. Barabash, Three-dimensional local residual stress and orientation gradients near graphite nodules in ductile cast iron, Acta Mater. 121 (2016) 173-180. doi:10.1016/j.actamat.2016.09.009.

[13] Y.B. Zhang, T. Andriollo, S. Fæster, W. Liu, A. Sturlason, R. Barabash, Synchrotron measurements of local microstructure and residual strains in ductile cast iron, in: IOP Conf. Ser. Mater. Sci. Eng., 2017. doi:10.1088/1757-899X/219/1/012054.

[14] K. Mukherjee, S. Fæster, N. Hansen, A.B. Dahl, C. Gundlach, J.O. Frandsen, A. Sturlason, Graphite nodules in fatigue-tested cast iron characterized in 2D and 3D, Mater. Charact. 129 (2017) 169-178. doi:10.1016/j.matchar.2017.04.024.

[15] M. Górny, E. Tyrała, Effect of cooling rate on microstructure and mechanical properties of thinwalled ductile iron castings, J. Mater. Eng. Perform. 22 (2013) 300-305. doi:10.1007/s11665-0120233-0.

[16] M. Górny, D.M. Stefanescu, Thin-Wall Ductile Iron Castings, in: D.M. Stefanescu (Ed.), ASM Handbook, Cast Iron Sci. Technol., ASM International, 2017: pp. 617-628.

[17] G.C. Weatherly, A Determination of the Punching Stress at the Interface of Particles during Rapid Quenching, Met. Sci. J. 2 (1968) 237-240. doi:10.1179/030634568790443143.

[18] B.C. Larson, L.E. Levine, Submicrometre-resolution polychromatic three-dimensional X-ray microscopy, J. Appl. Crystallogr. 46 (2013) 153-164. doi:10.1107/S0021889812043737.

[19] B.C. Larson, W. Yang, G.E. Ice, J.. Budai, J.. Tischler, Three-dimensional X-ray structural microscopy with submicrometre resolution, Nature. 415 (2002) 887-890.

[20] L.E. Levine, B.C. Larson, W. Yang, M.E. Kassner, J.Z. Tischler, M.A. Delos-Reyes, R.J. Fields, W. Liu, X-ray microbeam measurements of individual dislocation cell elastic strains in deformed singlecrystal copper., Nat. Mater. 5 (2006) 619-622. doi:10.1038/nmat1698.

[21] T. Andriollo, J. Thorborg, N. Tiedje, J. Hattel, A micro-mechanical analysis of thermo-elastic 
properties and local residual stresses in ductile iron based on a new anisotropic model for the graphite nodules, Model. Simulations Mater. Sci. Eng. 055012 (2016) 1-19. doi:10.1088/09650393/24/5/055012.

[22] T. Andriollo, K. Hellström, M.R. Sonne, J. Thorborg, N. Tiedje, J. Hattel, Uncovering the local inelastic interactions during manufacture of ductile cast iron: How the substructure of the graphite particles can induce residual stress concentrations in the matrix, J. Mech. Phys. Solids. 111 (2018) 333-357. doi:10.1016/j.jmps.2017.11.005.

[23] W. Liu, P. Zschack, J.Z. Tischler, G.E. Ice, B.C. Larson, X-ray laue diffraction microscopy in 3D at the advanced photon source, AIP Conf. Proc. 1365 (2010) 108-111. doi:10.1063/1.3625316.

[24] Y.B. Zhang, J.D. Budai, J.Z. Tischler, W. Liu, R. Xu, E.R. Homer, A. Godfrey, D. Juul Jensen, Boundary migration in a 3D deformed microstructure inside an opaque sample, Sci. Rep. 7 (2017). doi:10.1038/s41598-017-04087-9.

[25] W. Liu, G.E. Ice, B.C. Larson, W. Yang, J.Z. Tischler, J.D. Budai, The three-dimensional X-ray crystal microscope: A new tool for materials characterization, Metall. Mater. Trans. A. 35 (2004) 1963-1967. doi:10.1007/s11661-004-0145-1.

[26] S. Dhar, Y. Zhang, R. Xu, H.K. Danielsen, D. Juul Jensen, Synchrotron X-ray measurement of residual strain within the nose of a worn manganese steel railway crossing, in: IOP Conf. Ser. Mater. Sci. Eng., 2017. doi:10.1088/1757-899X/219/1/012016.

[27] H.K.D.H. Bhadeshia, S.A. David, J.M. Vitek, R.W. Reed, Stress induced transformation to bainite in pressure vessel steel, Mater. Sci. Technol. 7 (1991) 686-698. doi:10.1179/026708391790184915.

[28] P.J. Konijnenberg, S. Zaefferer, D. Raabe, Assessment of geometrically necessary dislocation levels derived by 3D EBSD, Acta Mater. 99 (2015) 402-414. doi:10.1016/j.actamat.2015.06.051.

[29] H. Gao, Y. Hang, W.D. Nix, J.W. Hutchinson, Mechanism-based strain gradient plasticity - I. Theory, J. Mech. Phys. Solids. 47 (1999) 1239-1263. doi:10.1016/S0022-5096(98)00103-3.

[30] L.P. Kubin, A. Mortensen, Geometrically necessary dislocations and strain-gradient plasticity: A few critical issues, Scr. Mater. 48 (2003) 119-125. doi:10.1016/S1359-6462(02)00335-4.

[31] N. Bonora, A. Ruggiero, Micromechanical modeling of ductile cast iron incorporating damage. Part I: 
Ferritic ductile cast iron, Int. J. Solids Struct. 42 (2005) 1401-1424.

doi:10.1016/j.ijsolstr.2004.07.025.

[32] H. Ledbetter, M. Austin, Internal strain (stress) in an SiC-Al particle-reinforced composite: an X-ray diffraction study, Mater. Sci. Eng. 89 (1987) 53-61.

http://www.sciencedirect.com/science/article/pii/0025541687902497.

[33] J.D. Eshelby, The Determination of the Elastic Field of an Ellipsoidal Inclusion, and Related Problems, Proc. R. Soc. A Math. Phys. Eng. Sci. 241 (1957) 376-396. doi:10.1098/rspa.1957.0133.

[34] E.U. Lee, Thermal stress and strain in a metal matrix composite with a spherical reinforcement particle, Metall. Trans. A. 23A (1992) 2205-2210.

[35] Y. Huang, H. Gao, W.D. Nix, J.W. Hutchinson, Mechanism-based strain gradient plasticity - II. Analysis, J. Mech. Phys. Solids. 48 (2000) 99-128. doi:10.1016/S0022-5096(99)00022-8.

[36] M.R. Watts, P.J. Withers, The interpretation of x-ray stress measurements of metal matrix composites using computer modelling techniques, in: M.L. Scott (Ed.), 11th Int. Conf Compos. Mater., 1997: pp. $32-42$.

[37] K. Theuwissen, J. Lacaze, M. Véron, L. Laffont, Nano-scale orientation mapping of graphite in cast irons, Mater. Charact. 95 (2014) 187-191. doi:10.1016/j.matchar.2014.06.021.

[38] T. Andriollo, S. Fæster, G. Winther, Probing the structure and mechanical properties of the graphite nodules in ductile cast irons via nano-indentation, Mech. Mater. 122 (2018) 85-95. doi:10.1016/j.mechmat.2018.03.010. 